\title{
Assessment of Health Literacy and Health Risk Behaviors among Elderly at Assiut City Egypt
}

\author{
Soher Ahmed Awad ${ }^{1}$, Hoda Diab Fahmy ${ }^{2}$, Rabaa Hamed Hassanen ${ }^{3}$ \& Saieda Abd-El Hameed Abd-ELaziz ${ }^{4}$
}

1. Assistant lecturer of Gerontological Nursing Department, Faculty of Nursing, Assiut University, Egypt.

2. Professor of Community and Family Health Nursing Department, Faculty of Nursing, Assuit University, Egypt.

3. Assistant professor of Community and Family Health Nursing Department, Faculty of Nursing, Assuit University, Egypt.

4. Lecturer of Gerontological Nursing Department, Faculty of Nursing, Assiut University, Egypt.

\begin{abstract}
Elderly people with inadequate health literacy less mindful of health behaviors significance. Study $\quad$ 1: assess health literacy and health risk behaviors among elderly people in Assiut city. Design: descriptive design was utilized in this study. Settings: the study carried out at two geriatric clubs in Assiut city (Geriatric club in Legitimacy Assembly and Geriatric club of Islamic cultural center). Convenient sample was used after (Total coverage of all elderly club members who agreed to participate in the study were included in the study, their number were 200 elderly participants aged 60 years and above). Four tools were used. Tool I: self administrative questionnaire sheet: include personal characteristics and health risk behaviors related questions. Tool II: body mass index calculation. Tool III: assessment of health literacy scale to assess health literacy level. Tool IV: Rapid Estimate of Adult Literacy in Medicine Scale to assess health literacy grade. Results: $75 \%$ of elderly participants had inadequate level of health literacy, also there was statistical significant difference between health literacy level and age $\mathrm{P}=0.034$. Conclusion: inadequate health literacy associated with health risk behaviors and over counter medications. Recommendation: Periodical educational program for elderly people to increase health literacy level about health risk behaviors.
\end{abstract}

Key Words: Health Literacy, Elderly, Health Risk Behaviors \& Nursing Role.

\section{Introduction}

Limited health literacy among elderly population in the United States, was $48 \%$ (United States Institute of Medicine, 2014). Patients with inadequate health literacy are often embarrassed to seek help thus try to conceal the fact by professing to themselves and to potential others that they are capable to read and understand health information (Lambert, 2014).

In Egypt the percent of elderly people "defined as 60 years and more" was $4.4 \%$ in $1976,5.75 \%$ in 1996 , rising to $6.27 \%$ in $2006,6.9 \%$ in 2015 . The percentage is projected to be $9.2 \%$ in 2021 , and it is expected to reach $20.8 \%$ in 2050 . This means that, around 20 million Egyptians will be categorized as elderly by that time; this is a big number that resembles a full nation in some parts of the world as elderly dependency ratio was 8.2 in 2017 (Egypt Demographics Profile 2018).

Health literacy described as social skills and cognitive that define the ability and motivation of peoples to gain, use and understand information to maintain and improve health (WHO, 2016). People with inadequate health literacy had poor health knowledge, poor self-management skills about chronic disease, preventive services lower use, and there is indirect pathway between health outcomes and inadequate health literacy (Wolf et al., 2015).
Health behavior is an action to maintain, attain, or regain good health and to prevent illness. Some common health behaviors are exercising regularly, eating a balanced diet, and obtaining necessary inoculations. Health behaviors are influenced by the social, cultural and physical environments in which we live and work (Misty et al., 2016).

Any activity done by people with intensity or frequency which increases injury or disease risk defined as health-risk behavior, it might cluster together into a risky lifestyle. Health literacy related to health outcomes through health behaviors as physical activity, fruit and vegetable consumption, smoking behavior, breakfast consumption, and body mass index, all of which are known to be linked to health status and health outcomes (Misty et al., 2016).

In clinical settings the gerontological nurse have the ability to increase level of health literacy and improve the communication between healthcare professions and patients. Nurses are also advocate for interventions to promote health literacy and improve health outcomes of older people in order to maximize their capacity to self-management. Empowering patients is a key factor in the success of a gaining patient's confidence (Miller, 2015). 


\section{Significance of the study}

Limited comprehensive health literacy was $81 \%$ among attendees outpatient clinics at Hospitals of Ain Shams University, Egypt (Almaleh et al., 2017). Prevalence of some health risk behaviors as smoking $40.5 \%$ of men, $0.3 \%$ of women, and $20.3 \%$ of Egypt's population overall are daily tobacco smokers (WHO, 2013) $53.1 \%$ of elderly members of assiut geriatric clubs were Overweight/ obese, and $25.5 \%$ of them reported higher musculoskeletal problem like rheumatoid arthritis, osteoarthritis and osteoporosis which result in low physical activity (Abou Faddan, et al., 2013) So this study was suggested to examine the relationship between health risk behaviors and health literacy level in Assiut city.

Study aim: To assess health literacy level \& health risk behaviors among elderly people in Assiut city.

Study question: Is there a relationship between health literacy level and health risk behaviors among elderly people?

\section{Materials \& Method}

Research design: Descriptive research design was used.

Setting: The study was carried out in two geriatric clubs at Assiut city (Geriatric club in Legitimacy Assembly and Geriatric club of Islamic cultural center).

Sample: Convenient sample (Total coverage of all elderly members who agreed to participate in the study) was used to assess health literacy level and health risk behaviors among elderly participants (male \& female), their number were 200 elderly participants aged 60 years and above.

\section{Study tools: Four tools were used}

Tool I: Self administered questionnaire:- It was developed by the researchers for collection of data. It based on relevant literature (Andréa et al., 2017) \& (Taylor, 2016) It consisted of 5 parts:- Part one:- it include personal characteristics as, age, sex, occupation, ...etc.

Part two: it include history of chronic diseases as diabetes mellitus, hypertension, and cardiovascular disease.

Part three: it include questions to assess polypharmacy as numbers of drugs used per day, self use of drugs, and self stopping of drugs, ...etc.

Part four: it include eating habits assessment as frequency of meals, vegetables, fruits, caffeine and amount of water/day.

Part five: it include questions to assess physical exercises as:- practice regular exercises, and frequency of exercise per week (1 time per week, 2 times per week, 3 times per week, 4 times per week). (NHIS 1995 \& Modified 2013).
Tool II: Body mass index calculation (BMI): By measuring height $\&$ weight then calculate body mass index by divided weight in kilograms on height in squared meters (WHO, 2015). Underweight $(<18.5)$, Overweight (25.0-29.9), Normal (18.5-24.9) and Obesity $(\geq 30.0)$.

Tool III: Health Literacy assessment questions:- to assess health literacy level using three self-report screening questions. These questions from a validated health literacy instrument (Chew et al., 2008).

Scoring system: Participants answered questions on a 3-point likert scale, (always, sometimes, and never) scores ranging $(0,1$, and 2$)$ respectively. The participants classified into a group with adequate health literacy (score $60 \%$ or higher) and group with inadequate health literacy (score less than $60 \%$ ).

Tool IV: Rapid Estimate of Adult Literacy in Medicine Scale (REALM):- Davis, et al. (1993): It consisted of (66 words) that the elderly people can read aloud and pronounce correctly, each within five seconds.

Scoring system: Score was added up the number of words pronounced correctly, $0-18$ words $3^{\text {rd }}$ grade or below, while $19-44$ words $4^{\text {th }}$ to $6^{\text {th }}$ grade, also $7^{\text {th }}$ to $8^{\text {th }}$ grade read 45-60 words, and high grade of health literacy read 61-66 words.

Validity \& Reliability of the tools:-

Tool I was tested for their its content validity by a group of five experts in community and gerontological health nursing. The required modifications were done. Testing reliability of the study tools was done by to alpha Cronbach test and the test result was $r=0.8$.

\section{Methods}

I- Preparatory stage: Official letter of endorsement was accomplished from the nursing faculty dean, to chiefs of geriatric clubs in Assiut city. The letter incorporated an endorsement to do the study, the nature and reason for the study.

II- Pilot study: Pilot study was carried out before starting of data collection on (10\% of elderly participants) who excluded from the study. The aim of pilot study is to test the clarity of the tools and to estimate the time needed for fulfilling it. Based on the results of pilot study, the necessary modifications in sheet were done.

III- Ethical Consideration: Nursing faculty ethical committee approved the research proposal. There was no risk for study subject during application of the research. Clinical research ethical principles was followed in the study. The right of refusing to participate to every elderly participants was assured and withdraw at any time from the study without any rational.

VI- Field work: The study started from $15^{\text {th }}$ of March 2017 to $15^{\text {th }}$ of May 2017. The assessment 
was done on all the study sample (200) elderly participants; the data was collected 3 days / week at afternoon time, average number of elderly met /day was 8-9. The self-administered questionnaire filled by the elderly themselves. The length of each interview took from 25-30 minutes. The researchers were available in the club to answer any questions and for further explanations.
V- Statistical analysis: The obtained data were reviewed, prepared for computer entry, coded, analyzed and tabulated. Descriptive statistics (frequencies, mean $\& \pm$ standard deviation) were done using computer program SPSS version 22, Excel 2010, analysis of variance done by using chi-square test $\mathrm{P}$ - Value $<0.05$.

\section{Results}

Table (1): Distribution of socio-demographic characteristics among elderly participants in geriatric clubs at Assiut city, 2017. N=200.

\begin{tabular}{|c|c|c|}
\hline Socio-demographic data & No. & $\%$ \\
\hline \multicolumn{3}{|l|}{ Age (years) } \\
\hline $60-69$ & 185 & 92.5 \\
\hline$\geq 70$ & 15 & 7.5 \\
\hline Mean+SD & \multicolumn{2}{|c|}{$65.39 \pm 3.226$} \\
\hline \multicolumn{3}{|l|}{ Sex } \\
\hline Male & 33 & 16.5 \\
\hline Female & 167 & 83.5 \\
\hline \multicolumn{3}{|l|}{ Marital status } \\
\hline Married & 177 & 88.5 \\
\hline Divorced & 9 & 4.5 \\
\hline Widowed & 14 & 7.0 \\
\hline \multicolumn{3}{|l|}{ Level of education } \\
\hline Read \& Write & 16 & 8.0 \\
\hline Primary education & 45 & 22.5 \\
\hline Secondary education & 114 & 57.0 \\
\hline University education & 25 & 12.5 \\
\hline \multicolumn{3}{|l|}{ Current occupation } \\
\hline Free business & 51 & 25.5 \\
\hline House wife & 37 & 18.5 \\
\hline Retired & 98 & 49.0 \\
\hline Employer & 14 & 7.0 \\
\hline \multicolumn{3}{|l|}{ Residential state } \\
\hline Spouse & 117 & 64.5 \\
\hline Son & 60 & 30.0 \\
\hline Daughter & 2 & 1.0 \\
\hline Alone & 9 & 4.5 \\
\hline \multicolumn{3}{|l|}{ Income } \\
\hline$<1000 \mathrm{LE}$ & 88 & 44.0 \\
\hline$\geq 1000 \mathrm{LE}$ & 112 & 56.0 \\
\hline \multicolumn{3}{|l|}{ Smoking status } \\
\hline Yes & 28 & 14.0 \\
\hline No & 172 & 86.0 \\
\hline
\end{tabular}




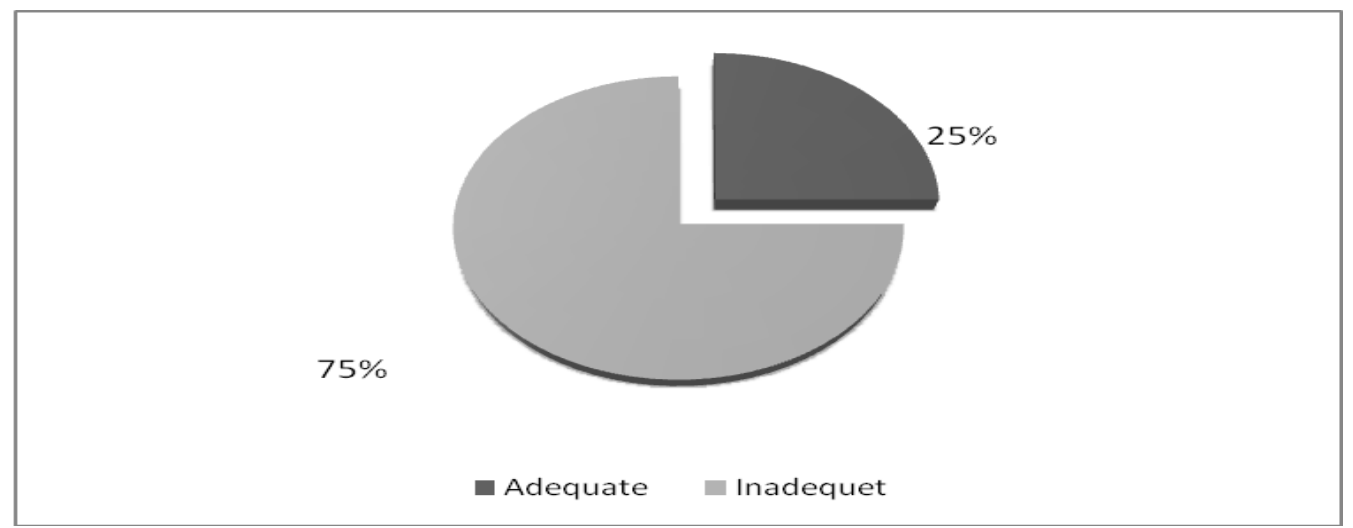

Figure 1: Health literacy level among elderly participants in geriatric clubs at Assiut city, 2017. N=200.

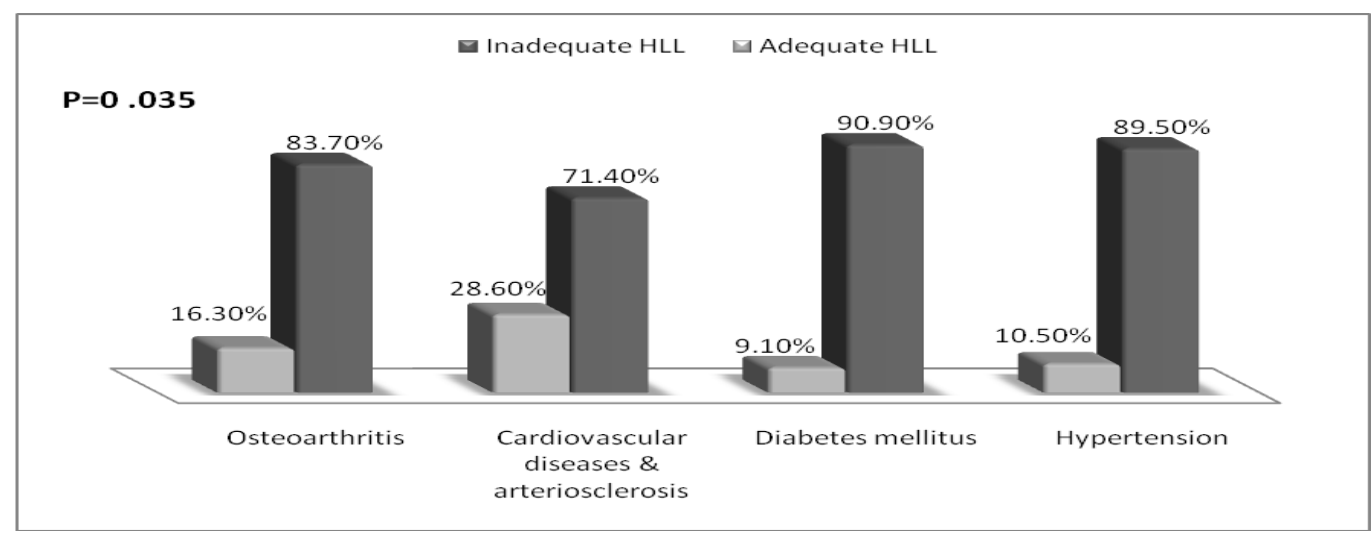

Figure (2): Relationship between chronic illness and HLL among elderly participants in geriatric clubs at Assiut city, 2017. N=200.

Table (2): Relation between health literacy level and health risk behaviors among elderly participants in geriatric clubs at Assiut city, 2017. $\mathrm{N}=\mathbf{2 0 0}$.

\begin{tabular}{|c|c|c|c|c|c|c|}
\hline \multirow{3}{*}{ Health risk behaviors } & \multicolumn{4}{|c|}{ Health literacy } & \multirow{3}{*}{$x^{2}$ test } & \multirow{3}{*}{ P-value } \\
\hline & \multicolumn{2}{|c|}{ Adequate $(n=50)$} & \multicolumn{2}{|c|}{ Inadequate $(n=150)$} & & \\
\hline & No. & $\%$ & No. & $\%$ & & \\
\hline \multicolumn{5}{|l|}{ Physical exercise (per week) } & \multirow{3}{*}{126.403} & \multirow{3}{*}{$0.000 *$} \\
\hline Regular & 40 & 80.0 & 5 & 3.3 & & \\
\hline Irregular & 10 & 20.0 & 145 & 96.7 & & \\
\hline \multicolumn{5}{|l|}{ Body mass index $(\mathrm{kg} / \mathrm{m} 2)$} & \multirow[t]{5}{*}{70.944} & \multirow[t]{5}{*}{$0.000 *$} \\
\hline$<18.5$ & 5 & 10.0 & 10 & 6.7 & & \\
\hline $18.5-24.9$ & 30 & 60.0 & 10 & 6.7 & & \\
\hline $25-29.9$ & 4 & 8.0 & 51 & 34.0 & & \\
\hline$\geq 30$ & 11 & 22.0 & 79 & 52.6 & & \\
\hline \multicolumn{5}{|l|}{ Smoking status } & \multirow[t]{3}{*}{64.008} & \multirow[t]{3}{*}{0.000} \\
\hline Smoker & 24 & 48.0 & 4 & 2.7 & & \\
\hline Non smoker & 26 & 52.0 & 146 & 97.3 & & \\
\hline \multicolumn{5}{|l|}{ Poly-pharmacy } & \multirow[t]{3}{*}{12.087} & \multirow[t]{3}{*}{$0.000 *$} \\
\hline Yes & 8 & 16.0 & 65 & 43.3 & & \\
\hline No & 42 & 84.0 & 85 & 56.7 & & \\
\hline \multicolumn{5}{|l|}{ Caffeine consumption } & \multirow[t]{3}{*}{60.220} & \multirow[t]{3}{*}{$0.000 *$} \\
\hline Light (1-2 cups/day) & 48 & 96.0 & 49 & 32.7 & & \\
\hline Heavy ( $\geq 3$ cups/day) & 2 & 4.0 & 101 & 67.3 & & \\
\hline
\end{tabular}

* Means there is significant difference 
Table (3): Relation between health literacy (HL) level and socio-demographic characteristics among elderly participants in geriatric clubs at Assiut city, 2017. $\mathrm{N}=200$.

\begin{tabular}{|c|c|c|c|c|c|c|}
\hline \multirow{3}{*}{ Socio-demographic data } & \multicolumn{4}{|c|}{ Health literacy } & \multirow{3}{*}{$x^{2}$ test } & \multirow{3}{*}{ P-value } \\
\hline & \multicolumn{2}{|c|}{ Adequate $(\mathrm{n}=50)$} & \multicolumn{2}{|c|}{ Inadequate $(n=150)$} & & \\
\hline & No. & $\%$ & No. & $\%$ & & \\
\hline \multicolumn{7}{|l|}{ Age (years) } \\
\hline $60-69$ & 43 & 86.0 & 142 & 94.7 & \multirow[t]{2}{*}{4.060} & \multirow[t]{2}{*}{ 0.043* } \\
\hline$\geq 70$ & 7 & 14.0 & 8 & 5.3 & & \\
\hline \multicolumn{5}{|l|}{ Sex } & \multirow{3}{*}{31.464} & \multirow{3}{*}{$0.000 *$} \\
\hline Male & 21 & 42.0 & 12 & 8.0 & & \\
\hline Female & 29 & 58.0 & 138 & 92.0 & & \\
\hline \multicolumn{5}{|l|}{ Level of education } & \multirow{6}{*}{59.6998} & \multirow{6}{*}{$0.0135^{*}$} \\
\hline Read \& Write & 0 & 0.0 & 16 & 10.7 & & \\
\hline Primary education & 5 & 10.0 & 40 & 26.6 & & \\
\hline Secondary education & 23 & 46.0 & 91 & 60.7 & & \\
\hline University education & 22 & 44.0 & 3 & 2.0 & & \\
\hline \multicolumn{5}{|l|}{ Current occupation } & & \\
\hline Free business & 9 & 18.0 & 42 & 28.0 & \multirow[t]{5}{*}{6.1607} & \multirow[t]{5}{*}{0.104} \\
\hline House wife & 9 & 18.0 & 28 & 18.7 & & \\
\hline Retired & 26 & 52.0 & 72 & 48 & & \\
\hline Employer & 6 & 12.0 & 8 & 5.3 & & \\
\hline \multicolumn{5}{|l|}{ Residential state } & & \\
\hline Spouse & 34 & 66.0 & 95 & 63.3 & \multirow{5}{*}{0.8809} & \multirow[t]{5}{*}{0.830} \\
\hline Son & 14 & 28.0 & 46 & 30.7 & & \\
\hline Daughter & 0 & 0.0 & 2 & 1.3 & & \\
\hline Alone & 2 & 4.0 & 7 & 4.7 & & \\
\hline \multicolumn{5}{|l|}{ Income } & & \\
\hline$<1000 \mathrm{LE}$ & 49 & 98.0 & 39 & 26.0 & \multirow[t]{2}{*}{78.896} & \multirow[t]{2}{*}{ 0.000* } \\
\hline$\geq 1000 \mathrm{LE}$ & 1 & 2.0 & 111 & 74.0 & & \\
\hline
\end{tabular}

*Means there is significant difference

Table (1): Cleared that $92.5 \%$ of the studied sample aged $60-69$ years, while $7.5 \%$ of them aged 75 years and older. The mean age was $65.39 \pm 3.226$, and $83.5 \%$ of the studied sample were female, while $16.5 \%$ of them were male. According to residence, $92.5 \%$ of them live in the urban area while $7.5 \%$ of them live in the rural areas. Concerning marital status, $88.5 \%$ of the studied sample were married.

Figure (1): Illustrated that $75 \%$ of elderly participants had inadequate level of health literacy, and only $25.0 \%$ of them had adequate health literacy level.

Figure (2): Showed that there was statistical significant relationship between health literacy level of participants and chronic illness $\mathrm{P}=0.035$, as $90.9 \%$ of diabetic patients had inadequate level of HL followed by hypertension $89.5 \%$.

Table (2): Showed that there was a statistical significant relationship between HL level of the studied sample and their physical exercise $(\mathrm{P}<0.000)$ as $96.7 \%$ of participants with inadequate HL had irregular physical activity. Regarding to Body mass index, there was a statistical significant difference between BMI of the studied sample and their level of HL $(\mathrm{P}<0.000)$ as $52.6 \%$ of participants with inadequate HL were obese. According to smoking status, there was st

Table (3): Revealed that there was statistical significant difference between age and health literacy level $(\mathrm{P}=0.043)$, as $94.7 \%$ of patients with inadequate HL aged from (60-69) years. Also there was statistical significant difference between sex and HL level $(\mathrm{P}=0.000)$. There was statistical significant difference between level of HL and residence $(\mathrm{P}=001)$, as $96 \%$ of urban participants had inadequate $\mathrm{HL}$, and there was statistical significant difference between HL level and level of education ( $\mathrm{P}=0.0135)$, as $60.7 \%$ of secondary educated participants had inadequate HL.atistical significant relationship between HL level of the studied sample and their smoking status $(\mathrm{P}<0.000)$. 


\section{Discussion}

As elderly persons' number increase in our nation, more consideration given to senior healthcare also successful ageing turning into an imperative subject in medical literature. Successful ageing idea become the first regarding older adults care preventive approach. Improving health literacy is the principle of non-pharmaceutical measures direct to elderly individuals (WHO, 2016) Low health literacy proficiency is adversely connected with health practices and health risk behaviors among elderly, numerous individuals in created nations had inadequate health literacy, which is related with different unwanted results, for example, poorer selfevaluated wellbeing (Taylor et al., 2016).

The present study showed that the majority of elderly participants aged 60-69 years with mean age 65.395+ 3.226 , also the present result found that low health literacy increase with age, this may explained by as people age became not motivated to gain more health information compared to younger ones, as there was significant relationship between age and health literacy level $\mathrm{P}=0.0043$, this is similar to Mark et al., (2016) who study Relationship of Functional Health Literacy to Patients' Knowledge of Their Chronic Disease in Torrance, and reported that $93.3 \%$ of the studied sample aged 60-69 years and there was significant relationship between age and health literacy level $(\mathrm{P}=0.001)$.

In this study female more likely to had inadequate health literacy level than male, this may be due to elderly female more occupied with other different duties than males as $83.5 \%$ of the studied sample were female, this is agreed to study done by Abd AL-Rahman, (2014) who study Health Literacy Prevalence among Elderly Care Givers and Its Impact on the Frequency of Elderly Hospitalization in Ain Shams, Egypt, and reported that more than half $(54.5 \%)$ of the studied sample were female.

Concerning level of education it was apparent that there was significant relationship between educational level and health literacy level $(\mathrm{P}=0.0135)$ as $60.7 \%$ of secondary educated participants had inadequate HL, this may be related to that educated people had health awareness regarding their health and seeking help as early as possible in reverse to illiterate ones. This is similar to Seyed et al., (2012) who study analysis of the association between polypharmacy and socioeconomic position among elderly in Sweden and found that inadequate HL was more prevalent among illiterate or could only read and write and reported that significant difference between education level \& HLL ( $\mathrm{P}=0.001)$.

Regarding income the present study found that there was significant relationship between health literacy level and income $(\mathrm{P}=0.0000)$ as more than one quarter of inadequate HLL of elderly participants had $<1000$ LE monthly income, this may be due to elderly persons with high income can use many different health services than those with low income. This agree with (Sijmen et al., 2016) who study Health Literacy Is Associated With Health Behaviors and Social Factors Among Older Adults in Netherlands and reported that low income is associated with low health literacy.

The present study showed that there was significant relation between health literacy level and physical activity ( $\mathrm{P}=0.000)$, as $96.7 \%$ of elderly participants with inadequate HL had irregular physical activity, this may be contributed to elderly with low literacy didn't know the benefits of regular physical exercises, also may be related to reduced or limited participation in the client-provider partnership.

This agree with Bas Geboers et al., (2016) who study Relationship between Health Literacy, Health Behaviors and Social Factors Among Older Adults reported statistically significant associations of low health literacy with insufficient physical activity $(\mathrm{p}<0.01)$. Also this is similar to results reported by Ahmed (2015) who study Effects of Moderate Aerobic Exercise on Cognitive in Older Adults, Egypt and founded that low levels of health literacy affects the ability to manage one's own health effectively as result there is negative impact on physical health. The present study illustrated that obesity prevalence among study participants was 45\%, this similar to Shebl et al., (2015) who study Prevalence \& Obesity Risk Factors among Elderly in Mansoura City and reported that prevalence of obesity among studied elderly was $33.3 \%$.

According to the results of the current study about three quarter $75 \%$ of the studied sample had low health literacy (inadequate health literacy), this agreed with study done by Abd AL-Rahman, (2014) who study Health Literacy Prevalence among Elderly Care Givers and Its Impact on the Frequency of Elderly Hospitalization in Ain Shams, Egypt, and found that $75 \%$ of the studied sample had low health literacy.

\section{Conclusion}

The present study concluded that: Low health literacy increases with people who had low educational level. Inadequate health literacy had a significant effect on health behaviors and is associated with improper medications use. There is a significant improvement in health literacy level about health risk behaviors among elderly participants in post and follow up test.

\section{Recommendations}

- The library of geriatric clubs should be include summarized booklets about health literacy and health risk behaviors. 
- The gerontological nurse should use HL assessment tool that assists understanding and responding to elders needs, and providing periodical health education program for elderly about health risk behaviors.

\section{References}

1. Abd Al-rahman T., (2014): Health Literacy Prevalence among Elderly Care Givers and Its Impact on the Frequency of Elderly Hospitalization in Ain Shams, Egypt, Advances in Aging Research, 3, Pp: 380-387.

2. Abou Faddan, H., Mohammed H., Darwish M., \& Ali H., Zarzour, (2013): morbidity profile and its relationship with diability among elderly people residing geriatric homes and geriatric clubs in assiut city Egypt. AAMJ, Vol. 11, N. 3, PP; 49-79.

3. Ahmed K., (2015): Effects of Moderate Aerobic Exercise on Cognitive in Older Adults, Corporation Oxidative Medicine Volume 2016, 8 pages.

4. Almaleh R., Helmy ${ }^{1}$ E., Farhat, H., Hasan A., Abdelhafez (2017): Assessment of health literacy among outpatient clinics at Ain Shams University Hospitals, Egypt: Public Health journal vol. 151, Pp 137-145.

5. Bas Geboers, R., Carel J., Jansen, \& Andrea F., (2016): Relationship between Health Literacy, Health Behaviors and Social Factors Among Older Adults: Journal of Health Communication, 21:sup2, 45-53.

6. Chew L., Griffin J., Partin M., Noorbalochi S., Grill J., (2008): Validation of screening questions for limited health literacyin a large VA outpatient population. J Gen Intern Med 2008;23:561-6.

7. Davis, T., Long, S., Jackson, R., (1993): Rapid Estimate of Adult Literacy in Medicine: Annals of Family Medicine, 25, Pp: 391-395.

8. Egypt Demographics Profile, (2018): Available at https://www.indexmundi.com/egypt/demograp hics_profile.html

9. Kobayashi, L., Wardle, J., Wolf, M., \& Von Wagner, C., (2015): Cognitive function and health literacy decline in a cohort of aging English adults. Journal of General Internal Medicine, 30, 958-964.

10. Lambert D., (2014): Adequate health literacy considered as being currency for negotiating the health care system and communicating effectively. National Academies Press. p. 1. ISBN 978-0-309-22029-3.

11. Mark C., Goodman E., (2016): Relationship of Functional Health Literacy to Patients'
Knowledge of Their Chronic Disease and Current Obesity Reports; 4(2) : 217-223.

12. Miller A., (2015): Nursing for Wellness in Older Adults, chapter 5, role of gerontological nurses, $7^{\text {th }}$ ed, America, Pp 742-743.

13. Misty A., Hawkins, Mary A., Dolansky, Jennifer B., Levin, (2016): Cognitive function and health literacy independently associated with heart failure knowledge, acute \& critical care journal, Vol. 45, 5, Pp 386-391.

14. National Health Interview Survey (NHIS), (2013): Available at: Promoting Health Literacy in Older Adults_files/tobacco_questions.pdf

15. Seyed I., Kristina J., Mats T., Johan F., (2012): Analysis of the association between poly-pharmacy and socioeconomic position among elderly aged $\geq 77$ years in Sweden Volume 30, Issue 2, Pages 419-427.

16. Shebl A., El Sayed Z., Mahmoud A., (2015): Prevalence \& Obesity Risk Factors among Elderly in Mansoura City Education \& Practice Journal. Vol.6, No.30, Pp 136-147.

17. Sijmen Carel J., Jansen, \& Andrea F., (2016): Health Literacy Is Associated With Health Behaviors and Social Factors Among Older Adults: Journal of Health Communication, 21:sup2, 45-53.

18. Taylor M., Wolfram, R., (2016): Healthy Eating for Older Adults, eat right, academy of nutrition and dietetics.

19. United State Institute of Medicine (2014): Health literacy: a prescription to end confusion. Washington DC: National Academies Press; 2014.

20. WHO (2016): Ageing and life-course, Health promotion for older people not business as usual, available at: http://www.who.int/gho/publications/health_pr omtion/2016/en/

21. Wolf M., Gazmararian J., \& Baker D., (2015): Health literacy and functional health status among older adults. Arch Intern Med 2015;165:1946-52

22. World Health Organization WHO, (2015): Body Mass Index (BMI) classification, available at:http://www.euro.who.int/en/healthtopics/disease-prevention/nutrition/a-healthylifestyle/body-mass-index

23. World Health Organization. Egypt and smoking profile, (2013): Available at http://www.who.int/ Egypt and smoking /en/webcite. 